\title{
PAEDIATRIC HAEMATOLOGICAL MALIGNANCIES: AN INCIDENCE AND CLINICOPATHOLOGICAL STUDY
}

\author{
Revathi Ramakrishnan', Rani Kalavathy²
}

${ }^{1}$ Associate Professor, Department of Pathology, Theni Medical College, Theni.

2Professor, Department of Pathology, Theni Medical College, Theni.

\begin{abstract}
Paediatric cancer is considered $1 \%$ to $3 \%$ of all cancer cases. This is the second most common cause of death in children. In case of the haematological malignancies acute lymphoblastic leukaemia is the most common neoplasm that affects the children.
\end{abstract}

\section{MATERIALS AND METHODS}

Children presented with haematological and lymphoreticular malignancy referred during 2003-2005 were included in this study. The routine haematological evaluation reveals malignancies such as acute leukaemia, the slides were stained routinely with Leishman and Giemsa stains and further subjected to histochemical evaluation with special stain such as periodic Acid-Schiff and Sudan Black B. lymph node specimen with initially suspected lymphoma in the initial cytomorphological diagnosis were fixed in toto in buffered neutral formation and processed routinely; 3-5 micron sections were cut and stained with haematoxylin and eosin. Reticulin and CD makers were also applied in doubtful cases for final confirmation.

\section{OBSERVATION AND RESULTS}

This study covered a total of 63 paediatric haematological malignancies. In 63 haematological cancers observed, 42 were males $(66.67 \%)$ with age ranging from 2-15 yrs. (mean age 8.2 yrs.) and 21 were females (33.33\%) with age ranging from 2-14 yrs. (mean age 8.6 yrs.). The average incidence observed is $44.49 \%$; there was increased incidence of haematological malignancies in the age group of more than 10 yrs. The incidence of haematological/lymphoreticular malignancy is low at less than 2 yrs. and also the incidence is high in male children. In 45 haematological cancers, 32 cases were Acute Lymphoblastic Leukaemia [(ALL), (71.11\%)] and [11 Cases, 24.44\%)] were diagnosed as lymphoproliferative/lymphoma spill. Only 2 cases of Acute Myeloid Leukaemia (AML, $4.44 \%$ ) was observed in this study. In the 18 cases of lymphoreticular malignancies 15 cases were NHL, in which large cell anaplastic and lymphoblastic type was commonly observed. Only 3 cases of Hodgkin's disease was observed in this study. Cases were diagnosed initially as lymphoma, further confirmation with CD Marker - CD 30 for RS cell was also done.

\section{CONCLUSION}

In the present study of 63 cases of Paediatric haematological cancers evaluated with clinical light microscopy, histochemical and IHC, the acute lymphoblastic leukaemia is the commonest neoplasm in childhood. The histochemical stains shall have their value in differentiating acute leukaemias and in all cases of lymphoma final confirmation with CD marker for treatment and prognosis is the gold standard strategy/method.

\section{KEYWORDS}

Children, Haematology, Malignancy.

HOW TO CITE THIS ARTICLE: Ramakrishnan R, Kalavathy R. Paediatric haematological malignancies: an incidence and clinicopathological study. J. Evolution Med. Dent. Sci. 2016;5(69):4952-4957, DOI: 10.14260/jemds/2016/1125

\section{INTRODUCTION \\ Paediatric cancer is considered $1 \%$ to $3 \%$ of all cancer cases.} This is the second most common cause of death in children; $50 \%$ of the children with age group younger than 15 years suffer from leukaemia and lymphoma. The other $50 \%$ suffer from the solid tumours and CNS tumours, etc.

In case of the haematological malignancies, acute lymphoblastic leukaemia is the most common neoplasm that affects the children. Next one is the acute myeloid leukaemia and JMML. In case of lymphoma both HL and NHL can occur, but HL is most common.

Financial or Other, Competing Interest: None.

Submission 06-08-2016, Peer Review 20-08-2016,

Acceptance 22-08-2016, Published 26-08-2016.

Corresponding Author:

Dr. Revathi Ramakrishnan,

3/720,

Aavin Nagar,

Surveyor Colony,

Madurai-625007.

E-mail: revathiram67@gmail.com

DOI: $10.14260 /$ jemds/2016/1125
A number of genetic conditions associated with elevated risk of Childhood Cancers such as Down's Syndrome, NF - I and II, Beckwith-Wiedemann Syndrome, Tuberous Sclerosis and Li-Fraumeni Syndrome. The risk factors for the major paediatric cancer includes ionizing radiation, non-ionizing power frequency electromagnetic field, pesticides, parental occupational chemical exposures, dietary factors and environmental cigarette smoke. The role of viruses such as Polyomaviruses, EBV and HTLV in aetiologic importance is unclear.

The treatment of paediatric cancers improve the patient's survival rates significantly; $75 \%$ of the children can be cured on treatment. In general, there is diversity in the occurrence of paediatric neoplasm all over the world.

In this study, the actual incidence and presentation of paediatric neoplasm in semi-urban area is evaluated. Molecular cytogenetics, Immunohistochemistry and histochemical stains play a major role in determining the exact underlying pathology of various paediatric haematological malignancies. 


\section{MATERIALS AND METHODS}

Children presented with haematological and lymphoreticular malignancy referred during 2003-2005 were included in this study. A thorough clinical evaluation, routine haematological investigations, ultrasonogram and CT scan (In proportion of cases) were done in each case.

A detailed clinical history, family history, particularly consanguinity, socio-economic status and nutrition, personal history, particularly about the parental occupation and also similar neoplasms in other family members were also recorded.

The routine haematological evaluation when reveals malignancies such as acute leukaemia, the slides were stained routinely with Leishman and Giemsa stains and further subjected to histochemical evaluation with special stain such as periodic Acid-Schiff and Sudan Black B.

Lymph node specimen with initially suspected lymphoma in the initial cytomorphological diagnosis were fixed in toto in buffered neutral formation and processed routinely; 3-5 micron sections were cut and stained with haematoxylin and eosin. Reticulin and CD makers were also applied in doubtful cases for final confirmation.

\section{OBSERVATION AND RESULTS}

This study covered a total of 63 paediatric haematological malignancies. In 63 haematological cancers observed, 42 were males $(66.67 \%)$ with age ranging from $2-15$ yrs. (mean age 8.2 yrs.) and 21 were females (33.33\%) with age ranging from 214 yrs. (mean age 8.6 yrs.).

In the total number of haematological malignancies observed during the period from Jan-2003 to December-2005, the average incidence observed is $44.49 \%$.

When the children are divided into six groups (i.e. $<2$ yrs., 2-4 yrs., 5-6 yrs., 7-8 yrs., 9-10 yrs. and >10 yrs.) there was increased incidence of haematological malignancies in the age group of more than 10 yrs. followed by 3-4 yrs. and 5-6 yrs.

Table 2 shows the incidence of haematological/lymphoreticular malignancy is low at less than 2 yrs. and also it shows the incidence is high in male children (42 cases, $66.67 \%$ ) when compared with females (21 cases, $33.33 \%)$.

Most of the children with haematological/lymphoreticular malignancies were from surrounding villages with low socioeconomic status, presented with the clinical symptoms as given in Table 3.

Most of the children presented with a triad of fever, anaemia and splenomegaly as common presenting symptoms and generalised lymphadenopathy is the commonest presenting symptom in children with lymphoreticular malignancies exhibiting firm, discrete, non-tender enlargement of the lymph nodes. Gum hypertrophy is also present in case of AML (Fig. 1).

When paediatric haematological/lymphoreticular malignancies were divided, haematological cancers were observed in 45 cases (71.43\%) and lymphoid neoplasms in 18 cases $(28.57 \%)$. In 45 haematological cancers, 32 cases were acute lymphoblastic leukaemia [(Fig. 2 and Fig. 3) (ALL), (71.11\%)] and [11 Cases, (24.44\%)] were diagnosed as Lymphoproliferative/lymphoma spill (Fig. 6). Only 2 cases of Acute Myeloid Leukaemia (AML, 4.44\%) (Fig. 4 and Fig. 5) was observed in this study.
Similarly, the lymphoreticular malignancies were also divided as shown in Table 5.

In 18 cases 15 cases were NHL, (Fig. 6) in which large cell anaplastic and lymphoblastic type was commonly observed. Only 3 cases of Hodgkin's disease (Fig. 7) was observed in this study. Cases were diagnosed initially as lymphoma, further confirmation with CD Marker - CD 30 for RS cell was also done.

\section{Special Studies}

In 2 cases of Acute Myeloid Leukaemia and 11 cases of lymphoproliferative lesions, histochemistry (Fig. 8 and Fig. 9), (PAS and Sudan Black B (Fig. 10 to Fig. 12)) was done and the results were given in Table 6.

\section{Immunohistochemistry}

CD Makers - for NHL and Hodgkin Lymphomas was also undertaken and the results were given in the following Table 7 (Fig. 13 to Fig. 14).

\begin{tabular}{|c|c|c|c|c|}
\hline $\begin{array}{l}\text { Sl. } \\
\text { No. }\end{array}$ & Period & $\begin{array}{c}\text { Total } \\
\text { Haematological } \\
\text { Cancers }\end{array}$ & $\begin{array}{l}\text { Paediatric } \\
\text { Cancers }\end{array}$ & $\%$ \\
\hline 1 & \begin{tabular}{|c|} 
Jan 2003- \\
June \\
2003
\end{tabular} & 96 & 15 & $15.63 \%$ \\
\hline 2 & \begin{tabular}{|c|} 
July \\
2003-Dec \\
2003
\end{tabular} & 120 & 13 & $10.83 \%$ \\
\hline 3 & \begin{tabular}{|c|} 
Jan 2004- \\
June \\
2004 \\
\end{tabular} & 124 & 20 & $16.13 \%$ \\
\hline 4 & \begin{tabular}{|c|} 
July \\
2004-Dec \\
2004
\end{tabular} & 152 & 21 & $13.82 \%$ \\
\hline 5 & \begin{tabular}{|c|} 
Jan 2005- \\
June \\
2005 \\
\end{tabular} & 167 & 33 & $19.76 \%$ \\
\hline 6 & \begin{tabular}{|c|} 
July \\
$2005-D e c$ \\
2005
\end{tabular} & 2 & 30 & $12.82 \%$ \\
\hline & Table 1: Sho & Total Numbe & Iaemat & ical \\
\hline
\end{tabular}

\begin{tabular}{|c|c|c|c|c|c|}
\hline $\begin{array}{c}\text { Sl. } \\
\text { No. }\end{array}$ & Age & Male & Female & $\begin{array}{c}\text { Total } \\
\text { No. of } \\
\text { Cases }\end{array}$ & $\%$ \\
\hline 1 & $<2$ & 4 & - & 4 & $6.6 \%$ \\
\hline 2 & $3-4$ & 9 & 2 & 11 & $17.46 \%$ \\
\hline 3 & $5-6$ & 7 & 4 & 11 & $17.46 \%$ \\
\hline 4 & $7-8$ & 2 & 5 & 7 & $11.11 \%$ \\
\hline 5 & $9-10$ & 5 & 4 & 9 & $14.29 \%$ \\
\hline 6 & $>10$ & 15 & 6 & 21 & $33.33 \%$ \\
\hline \multicolumn{7}{|c|}{ Table 2: Incidence in Age } \\
\hline
\end{tabular}

\begin{tabular}{|c|c|c|c|}
\hline $\begin{array}{c}\text { Sl. } \\
\text { No. }\end{array}$ & Clinical Features & $\begin{array}{c}\text { No. of } \\
\text { Cases }\end{array}$ & $\%$ \\
\hline 1 & Fever & 48 & $76.19 \%$ \\
\hline 2 & Anaemia & 52 & $82.54 \%$ \\
\hline 3 & $\begin{array}{c}\text { Upper Respiratory Tract } \\
\text { Infection }\end{array}$ & 32 & $50.79 \%$ \\
\hline 4 & $\begin{array}{c}\text { Joint pain (Lower } \\
\text { extremity) }\end{array}$ & 15 & $23.79 . \%$ \\
\hline 5 & Bony tenderness & 2 & $3.17 \%$ \\
\hline 6 & $\begin{array}{c}\text { Gum Hypertrophy } \\
\text { (Fig.1) }\end{array}$ & 41 & $1.59 \%$ \\
\hline
\end{tabular}




\begin{tabular}{|c|c|c|c|}
\hline 7 & Chloromas & - & - \\
\hline 8 & $\begin{array}{c}\text { Generalised } \\
\text { Lymphadenopathy }\end{array}$ & 58 & $92.06 \%$ \\
\hline 9 & Splenomegaly & 55 & $87.30 \%$ \\
\hline 10 & Hepatomegaly & 38 & $60.32 \%$ \\
\hline 11 & Bleeding manifestation & 25 & $39.68 \%$ \\
\hline \multicolumn{3}{|c|}{ Table 3: Clinical Features } \\
\hline
\end{tabular}

\begin{tabular}{|c|c|c|c|}
\hline $\begin{array}{c}\text { Sl. } \\
\text { No. }\end{array}$ & $\begin{array}{c}\text { Haematological } \\
\text { Malignancy }\end{array}$ & $\begin{array}{c}\text { No. of } \\
\text { Cases }\end{array}$ & \% \\
\hline 1 & ALL & 32 & $71.11 \%$ \\
\hline 2 & AML & 2 & $4.44 \%$ \\
\hline 3 & JCMML & - & - \\
\hline 4 & CML & - & - \\
\hline 5 & $\begin{array}{c}\text { Lymphoproliferative/ } \\
\text { Lymphoma Spill }\end{array}$ & 11 & $24.44 \%$ \\
\hline \multicolumn{3}{|c|}{$\begin{array}{c}\text { Table 4: Shows the Number of Various } \\
\text { Haematological Malignancies }\end{array}$} \\
\hline
\end{tabular}

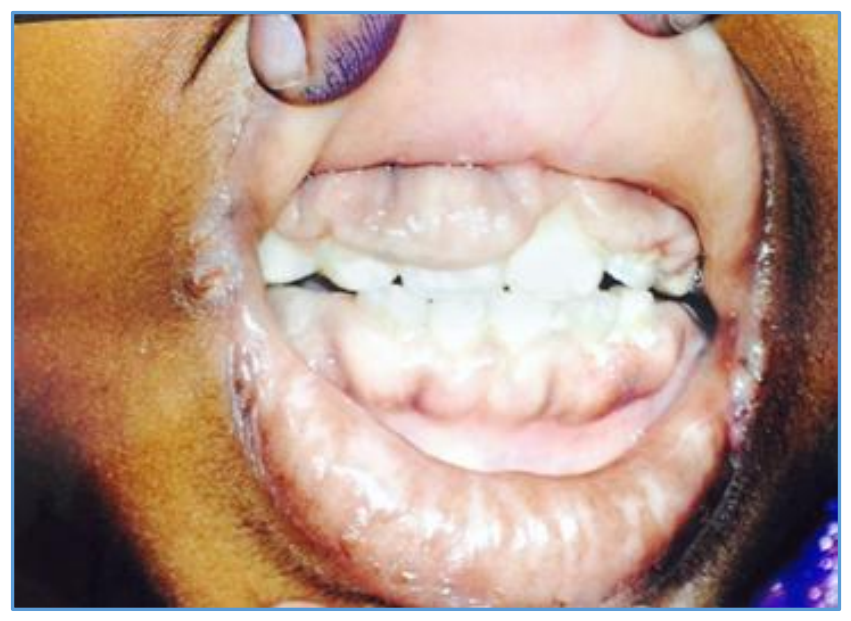

Fig. 1: Massive Gum Hypertrophy in Acute Myeloid Leukaemia in Six Year Old Female Child

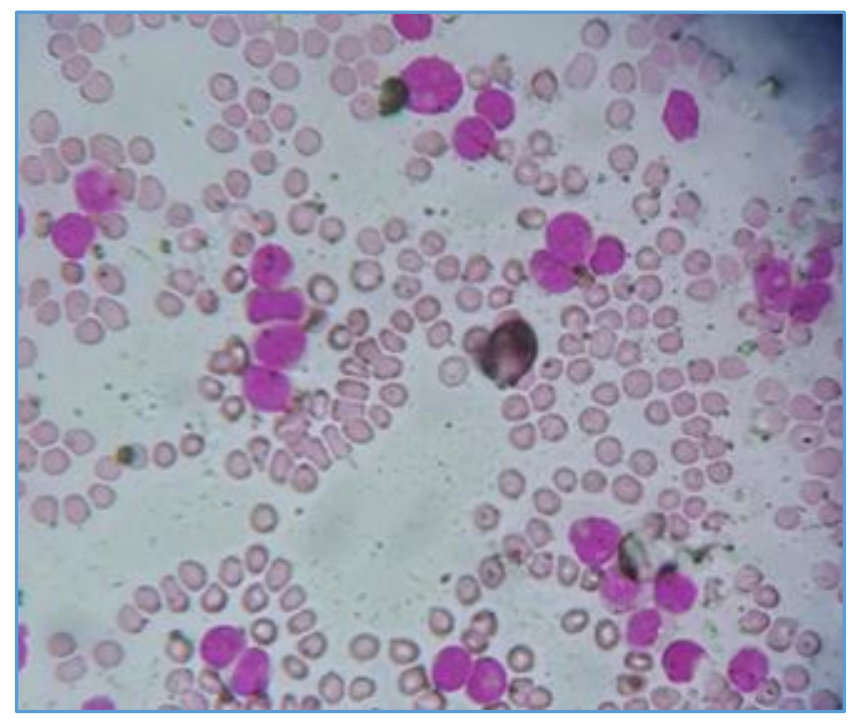

Fig. 2: Acute Lymphoblastic Leukaemia. Peripheral Smear shows Several Lymphoblasts with Condensed Chromatin and Scant Cytoplasm (Leishman's Stain X1000)

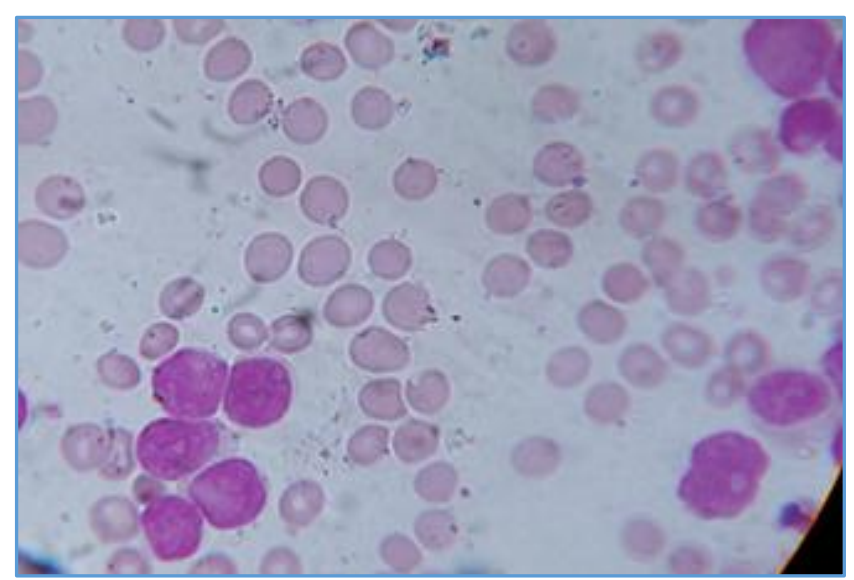

Fig. 3: Acute Lymphoblastic Leukaemia. Peripheral Smear shows Several Lymphoblasts with One or Two Nucleoli. (Leishman's Stain X1000) 


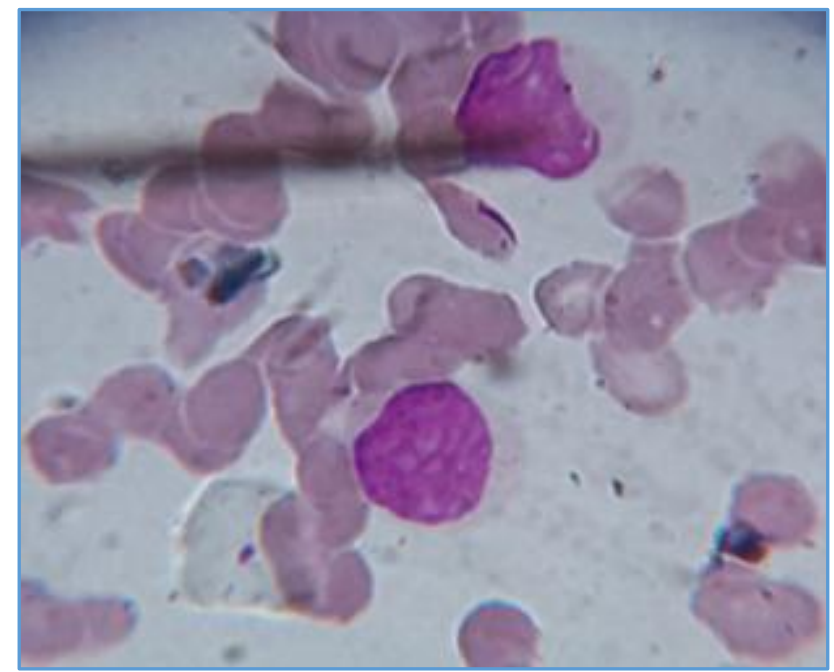

Fig. 4: Acute Myeloid Leukaemia. Peripheral Smear shows One Myelocyte and Metamyelocyte. (Leishman's Stain X1000)

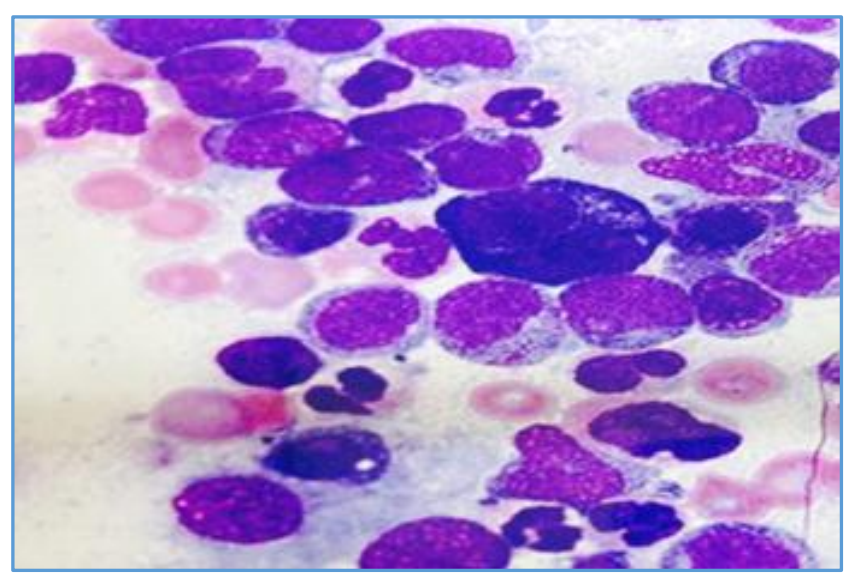

Fig. 5: Acute Myeloid Leukaemia. Bone Marrow Aspirate shows Several Myeloblasts with Multiple Nucleoli. (Leishman's Stain X1000)

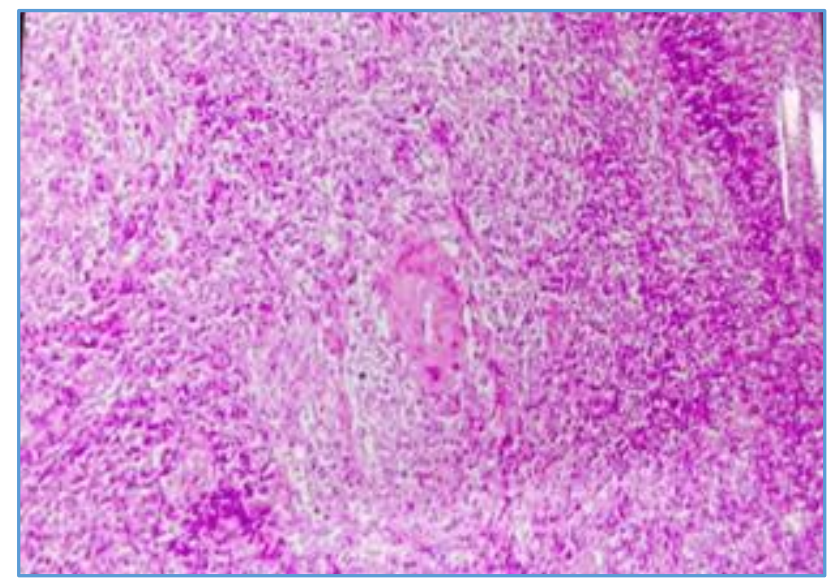

Fig. 6: Non-Hodgkin Lymphoma. Low Power View shows the Diffuse Effacement of the Lymph Node Architecture by Monotonous Populations of Neoplastic Lymphocytes. (H\&E X100)

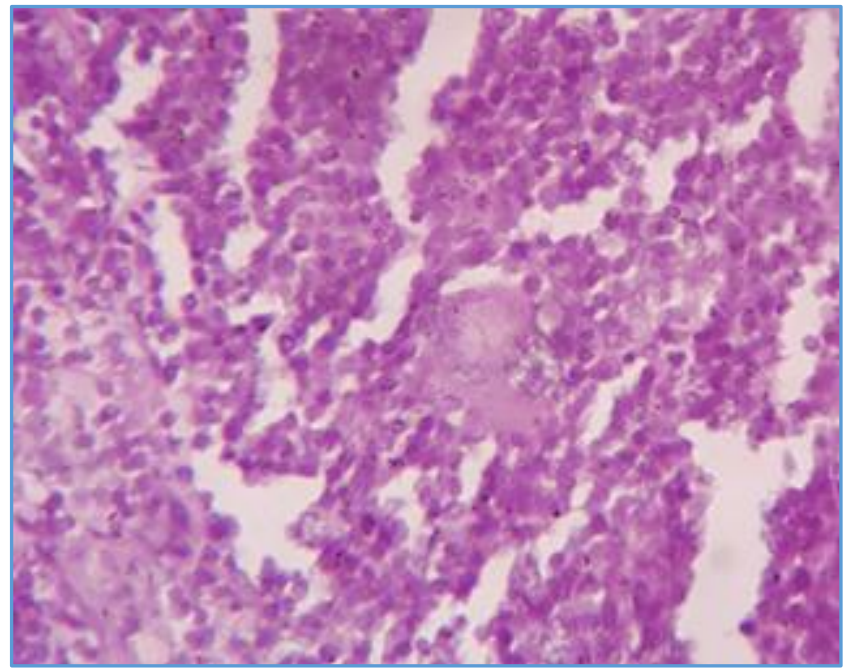

Fig. 7: Hodgkin Lymphoma. High Power View shows the Diffuse Effacement of the Lymph Node Architecture. (H\&E X400)

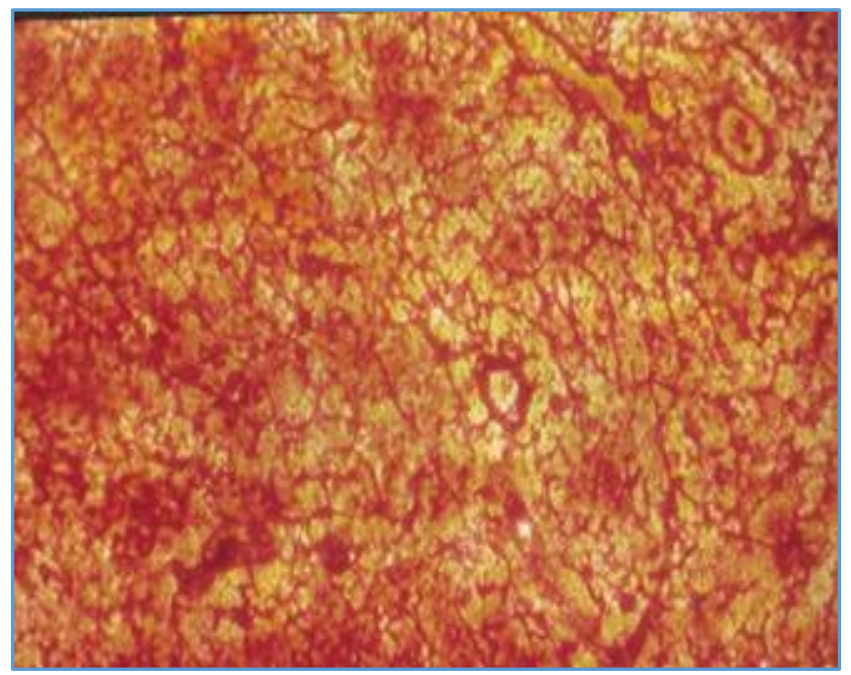

Fig. 8: Reactive Lymphadenitis Reticulin Stain

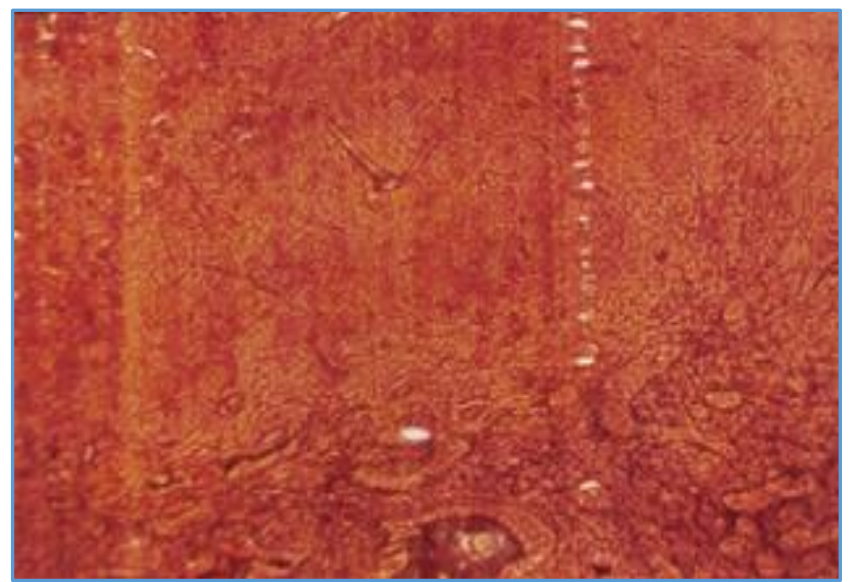

Fig. 9: Non-Hodgkin Lymphoma Reticulin Stain 


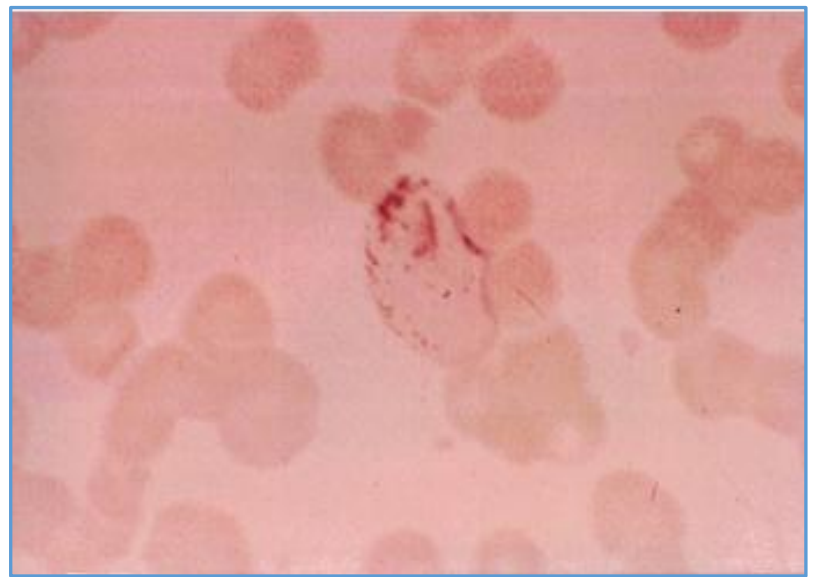

Fig. 10: Acute Myeloid Leukaemia Sudan Black B Positive Cells

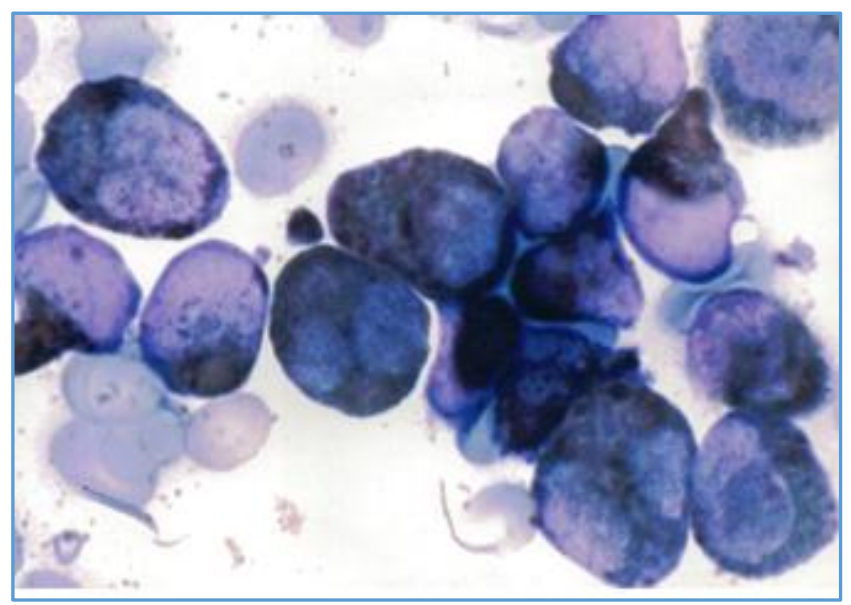

Fig. 11: Acute Myeloid Leukaemia Sudan Black B Positive - Auer Rods

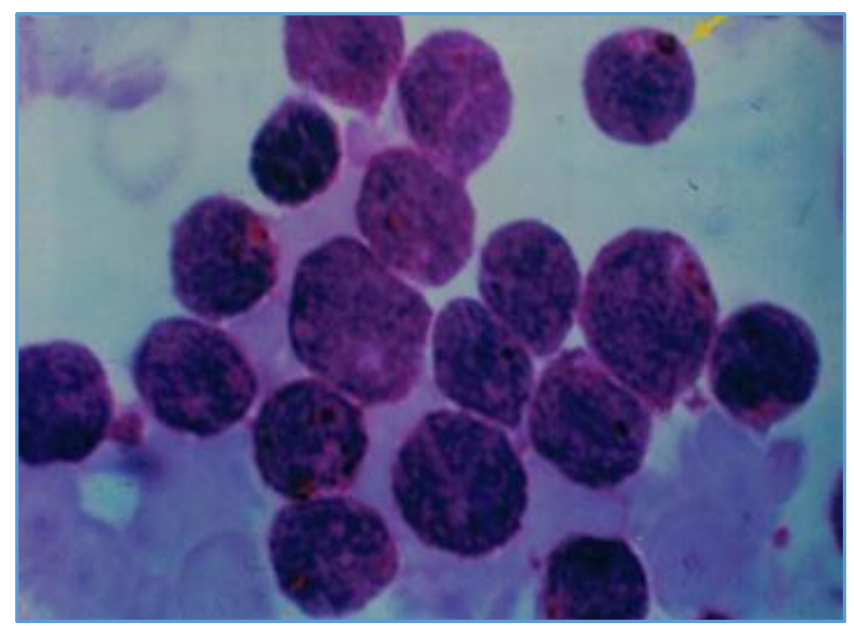

Fig. 12: Acute Lymphoblastic Leukaemia PAS Block Positive Cells

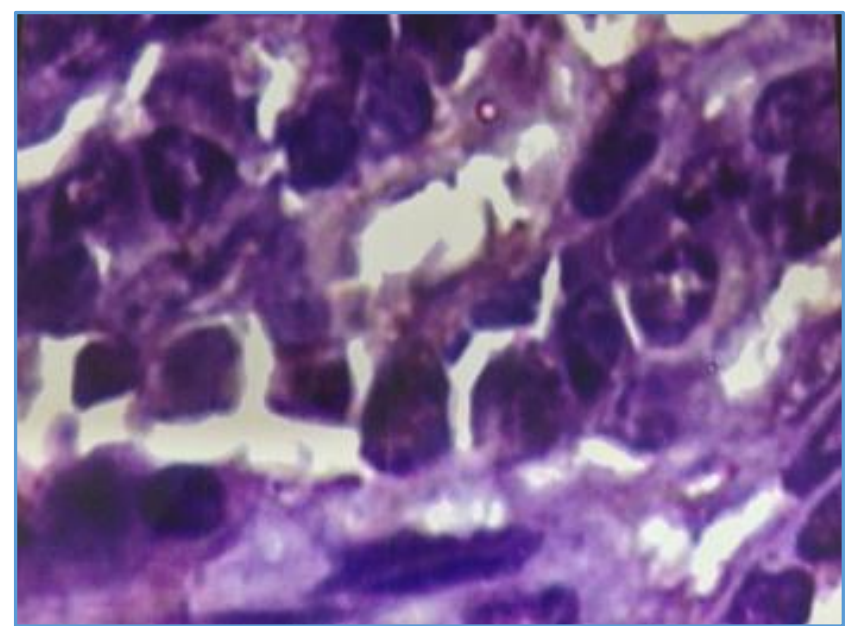

Fig. 13: NHL - Diffuse Large B Cell Lymphoma CD-20 Positive B Cells

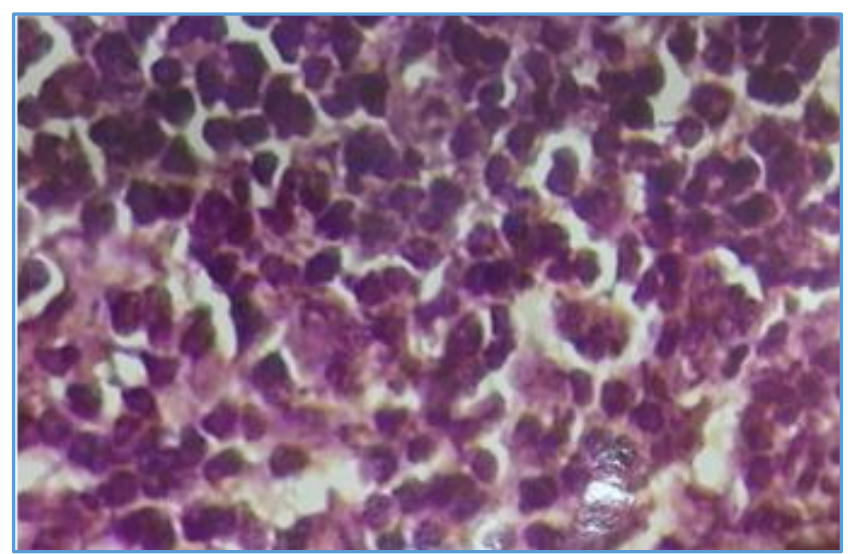

Fig. 14: NHL - Diffuse Large B Cell Lymphoma CD 3 Positive T Cells

\section{DISCUSSION}

Although cancer among children is relatively uncommon, it remains a significant cause of mortality in this population and is second only to accidents as a cause of death in the age group of 5-14 years. . $^{1,2,3}$

The incidence of Paediatric cancer is increasing in comparison with studies conducted by various research workers and literature. In our study the incidence of Paediatric haematological malignancies is $44.49 \%$, which is in correlation with studies conducted by Elizabeth Rosen, MD, Resident Physician. The average incidence of haematological Paediatric malignancy is 1 in 630 , and the relative rate of haematological cancer below 5 yrs. is $40 \%$.

In Western population, the increased incidence of haematological malignancies is observed below the age of 5 years. In our study, the Peak incidence of haematological malignancies is seen after 10 yrs. followed by $3-4$ yrs., which is in contrast with the studies conducted by Western Research Workers. Probably related to low socio-economic status, poor education and lack of knowledge regarding the initial alarming symptoms of haematological malignancies.

The most common haematological neoplasm in children is leukaemia and it also stands as most common malignancy. In our study, acute lymphoblastic leukaemia is the commonest haematological neoplasm followed by lymphoma/lymphoproliferative disorders, which is well in correlation with literature. $4,5,6$ 
In doubtful cases, use of histochemistry with Sudan-Black $B$ and PAS allows an initial, standard cost effective method, helpful in arriving at diagnosis.

One case of Hodgkin lymphoma 7,8 with total effacement of architecture and polymorphous population of lymphocytes with few RS-like cells when subjected to IHC $^{9}$ with $\mathrm{CD}$ marker CD-30, a classical RS cell marker revealed total negative staining for RS cells and positive for B cell markers of NHL.

Lymphomas comprise approximately $24.44 \%$ of all paediatric malignancies, making them the third most common cancer. Approximately, $60 \%$ of paediatric lymphomas are Non-Hodgkin's Lymphoma (NHL). Boys are affected more often than girls with a 3:1 ratio and the peak incidence of NHL is between the ages of 7 and 11 years.

Histologic varieties of NHL are divided into low-, intermediate- or high-grade categories based upon their clinical behaviour and over $90 \%$ of children have high-grade disease at presentation. High-grade lesions include large cell lymphomas, ${ }^{10,11,12}$ constitute about $27 \%$ of paediatric NHL. Lymphoblastic lymphoma occurs in $29 \%$ of paediatric cases. The small cell non-cleaved lymphomas are found in $34 \%$ of paediatric NHL and Burkitt's Lymphoma (BL) is the most common of this subtype.

The evaluation of the child suspected to have a lymphoma begins of course with a complete history and physical. Examination definitive diagnosis requires tissue for pathologic evaluation, which may be obtained by a tonsillectomy or open biopsy of an involved lymph node. Because most paediatric patients with NHL present with disseminated diseases, a complete staging work-up must be undertaken. This would include laboratory studies (to include LDH, LFTs and HIV), LP with CSF analysis, bilateral iliac crest bone marrow biopsy, CT of the chest, abdomen and pelvis and bone scan. The reasoning for such an extensive workup is that accurate clinical staging is of utmost importance in assigning patients to an appropriate treatment protocol. ${ }^{13,14}$

Hodgkin's Disease (HD) is less common in the paediatric population than NHL. This occurring in children under the age of 10 years. Boys are affected more frequently than girls (3:1), although this ratio narrows after puberty (1.4:1).

There are four histologic subtypes of HD-nodular sclerosing, mixed cellularity, lymphocyte predominance and lymphocyte depletion. Overall, nodular sclerosing and mixed cellularity are the most common subtypes of HD, but in the paediatric population the lymphocyte predominance and nodular sclerosing are seen most frequently.

HD will present with asymmetric lymph node enlargement in about $90 \%$ of cases. The lymphadenopathy is described as firm, rubbery and non-tender and in the neck most often involves the supraclavicular fossa. The most common extralymphatic site of HD is the spleen followed by the liver. Nearly one-third of patients will have associated constitutional symptoms at presentation including fever, night sweats, anorexia, weakness or loss of $10 \%$ or more of body weight.

\section{CONCLUSION}

In the present study of 63 cases of Paediatric haematological cancers evaluated with clinical light microscopy, Histochemical and IHC, following conclusions are made and presented.
1. In Haematological malignancy, acute lymphoblastic leukaemia is the commonest neoplasm in childhood.

2. Histochemical stains shall have their value in differentiating acute leukaemias.

3. In all cases of lymphoma, final confirmation with CD marker for treatment and prognosis is the gold standard strategy/method.

\section{REFERENCES}

1. Ries LAG, Smith MA, Gurney JG, et al. Cancer incidence and survival among children and adolescents: United States SEER program 1975-1995. National Cancer Institute SEER Program. 1999.

2. Gurney JG, Davis S, Severson RK, et al. Trends in cancer incidence among children in the U.S. Cancer 1996;78(3):532-41.

3. Gurney JG, Severson RK, Davis S, et al. Incidence of cancer in children in the United States. Sex-, race- and 1-year age-specific rates by histologic type. Cancer 1995;75(8):2186-95.

4. Urayama KY, Manabe A. Genomic evaluations of childhood acute lymphoblastic leukemia susceptibility across race/ethnicities. Rinsho Ketsueki 2014;55(10):2242-8.

5. Seiter K, Sarkodee-Adoo C, Talavera F, eds. Acute lymphoblastic leukemia. Medscape Reference. Web MD 2014.

6. Mora J, Filippa DA, Qin J, et al. Lymphoblastic lymphoma of childhood and the LSA2-L2 protocol: the 30-years experience at Memorial-Sloan-Kettering Cancer Center. Cancer 2003;98(6):1283-91.

7. Khan AR, Omer S, Rashid S, et al. Fine needle aspiration: diagnosis of nodal Hodgkin's lymphoma (Part - II). JK Practitioner 2002;9(4);264-7.

8. Armitage J. Early Hodgkin's lymphoma. The New England Journal of Medicine 2010;363(7):653-62.

9. Eichenauer DA, Engert A, Dreyling M. Hodgkin's lymphoma: ESMO clinical practice guidelines for diagnosis, treatment and follow-up. Annals of Oncology 2011;22(Suppl 6):vi55-8.

10. Sandlund JT, Ching-Hon $P$, Roberts WM, et al. Clinicopathologic features and treatment outcome of children with large cell lymphoma and the (2;5)(p23:q35). Blood 1994;84(8):2467-71.

11. Sandlund JT, Downing JR, Crist WM. Non-Hodgkin's lymphoma in childhood. The New England Journal of Medicine 1996;334(198):1238-48.

12. Seidemann K, Tiemann M, Schrappe M, et al. Short-pulse B-non-Hodgkin lymphoma-type chemotherapy is efficacious treatment for pediatric anaplastic large cell lymphoma: a report of Berlin-Frankfurt-Münster group trial NHL-BFM 90. Blood 2001;97(12):3699-706.

13. Franklin J, Paus MD, Pluetschow A, et al. Chemotherapy, radiotherapy and combined modality for Hodgkin's disease, with emphasis on second cancer risk. Cochrane Database Syst Rev 2005;(4):CD003187.

14. Herbst C, Rehan FA, Skoetz N, et al. Chemotherapy alone versus chemotherapy plus radiotherapy for early stage Hodgkin lymphoma. Cochrane Database Syst Rev 2011;(2):CD007110. 